\title{
Addition of Celebrex and Pregabalin to Ropivacaine for Posterior Spinal Surgery: A Randomized, Double-Blinded, Placebo-Controlled Trial
}

This article was published in the following Dove Press journal: Drug Design, Development and Therapy

\author{
Ye Zhang ${ }^{1} *$ \\ Bin $\mathrm{He}^{\prime}$ \\ Jinqiu Zhao ${ }^{2, *}$ \\ Muzi Zhang' \\ Qinsong Ren' \\ Wei Zhang' \\ Shuai $\mathrm{Xu}{ }^{\prime}$ \\ Zhengxue Quan' \\ Yunsheng Ou' \\ 'Department of Orthopedics, The First \\ Affiliated Hospital of Chongqing Medical \\ University, Chongqing, People's Republic of \\ China; ${ }^{2}$ Department of Infectious Diseases, \\ The First Affiliated Hospital of Chongqing \\ Medical University, Chongqing, People's \\ Republic of China \\ *These authors contributed equally to this \\ work
}

Correspondence: Bin He Email binheing@163.com
Background: Serious pain commonly occurs after posterior spinal surgery. This study aims to evaluate the effect of preemptive and multimodal analgesia using celebrex, pregabalin and ropivacaine on pain control after this surgery.

Methods: Ninety-three patients undergoing posterior spinal surgery were enrolled in this prospective, randomized, double-blind, placebo-controlled clinical trial. All patients were treated with patient- controlled analgesia (PCA, intravenous tramadol hydrochloride and flurbiprofen) as required. They were randomized to combination analgesia intervention (oral celebrex, pregabalin and subcutaneous infiltration of ropivacaine), ropivacaine intervention (only subcutaneous infiltration of ropivacaine), and control intervention (placebo). We compared postoperative visual analog scale (VAS) scores and PCA dose among the three groups.

Results: The VAS scores were significantly lower in the combination analgesia group than in the control group at $0 \mathrm{~h}, 2 \mathrm{~h}, 12 \mathrm{~h}, 24 \mathrm{~h}, 3 \mathrm{~d}, 5 \mathrm{~d}, 7 \mathrm{~d}$ and $14 \mathrm{~d}$ after posterior spinal surgery, while combination analgesia was also superior to ropivacaine in terms of VAS scores at $24 \mathrm{~h}$ and 14 $\mathrm{d}$ postoperatively. The combination analgesia group was also associated with significantly reduced PCA consumption compared with the control group, but there was no statistical difference in PCA consumption between the ropivacaine group and control group.

Conclusion: Combination analgesia using celebrex, pregabalin and ropivacaine is effective and safe to alleviate pain after posterior spinal surgery.

Clinical Trial Registration: Chinese Clinical Trial Registry No. ChiCTR2000031236.

Keywords: preemptive analgesia, multimodal analgesia, pain control, posterior spinal surgery, randomized trial

\section{Introduction}

With the aggravation of aging and an increase in accidents, the number of patients with degenerative lumbar diseases (e.g. lumbar disc herniation and spondylolisthesis) and spinal fracture has significantly increased, and posterior spinal surgery has been widely performed to treat these diseases. ${ }^{1,2}$ However, severe postoperative pain commonly occurs in these patients. The pain negatively affects postoperative satisfaction, hinders postoperative recovery and prolongs the hospitalization time..$^{3,4}$ Various approaches have been developed to relieve postoperative pain, improve rapid recovery and the quality of life. Perioperative analgesia mainly includes local infiltration, nerve block, intravenous and oral analgesics. ${ }^{5,6}$ In accordance with the pathological mechanisms of acute pain, preemptive and multimodal analgesia has shown important potential in alleviating postoperative pain. ${ }^{7}$ 
Non-steroidal anti-inflammatory drugs (NSAIDs) are commonly used for pain control through inhibiting cyclooxygenase and subsequent synthesis of prostaglandin E2. ${ }^{8}$ NSAIDs are documented to effectively inhibit the production of prostaglandins in the spinal cord and surrounding tissues, and thus relieve postoperative pain. ${ }^{9}$ Celebrex, a NSAID, serves as an important analgesic in osteoarthritis, hand surgery, hip and knee replacement, etc. ${ }^{10}$ As an antiepileptic drug, pregabalin can reduce central sensitivity by acting on the $\alpha-2-\delta$ subunit of voltage-gated calcium channels, thereby decreasing neurotransmitters associated with spinal pain. Pregabalin was reported to reduce the pain and opioid consumption after spinal surgery. ${ }^{11,12}$ NSAIDs and pregabalin can achieve a synergistic effect on analgesia. ${ }^{13,14}$ In addition, the local subcutaneous infiltration of ropivacaine has shown some ability of postoperative pain control. ${ }^{15,16}$

In this study, based on the hypothesis that preemptive and multimodal analgesia using celebrex, pregabalin and ropivacaine can reduce postoperative pain of posterior spinal surgery, we examined the impact of preemptive and multimodal analgesia (combination analgesia: oral celebrex and pregabalin in combination with subcutaneous infiltration of ropivacaine) on pain intensity and PCA dose after posterior spinal surgery. The aim of this double-blind, randomized, placebo-controlled study was to establish a therapeutic approach in reducing the pain intensity following posterior spinal surgery.

\section{Methods}

\section{Study Design and Population}

Ninety-three patients undergoing posterior spinal surgery were enrolled in this prospective, double-blind, randomized placebo-controlled clinical trial. This study was conducted in accordance with the Declaration of Helsinki and approved by the Ethics Committee of The First Affiliated Hospital of Chongqing Medical University (IRB \#20190701). Written informed consent was obtained from all subjects participating in the trial. The trial was registered prior to patient enrollment at the Chinese Clinical Trial Registry (ChiCTR2000031236, Principal investigator: Bin $\mathrm{He}$, Date of registration: March 25, 2020).

Patients were enrolled between March 2020 and July 2020. The inclusion criteria of this study were as follows: (1) ages 18-90, (2) single segment and double segments of posterior spinal fusion surgery because of lumbar disc herniation, spinal stenosis or spondylolisthesis, and (3) posterior reduction and fixation of thoracolumbar fracture. The exclusion criteria included allergy to amide anesthetics or sulfonamide, severe hepatic and renal dysfunction, bronchospasm, asthma, active gastrointestinal ulcer or bleeding, severe heart failure or creatinine clearance rate $<60 \mathrm{~mL} / \mathrm{min}$.

After submission of written informed consent, patients were randomized (1:1:1 ratio) to either combination analgesia intervention (oral celebrex [G.D. Searle LLC, USA], pregabalin [Qilu Pharmaceutical (Hainan) Co., Ltd, China] and subcutaneous infiltration of ropivacaine [Aspen Pharmacare Australia Pty Ltd, Australia]), ropivacaine intervention (only subcutaneous infiltration of ropivacaine), or control intervention (placebo) using a web-based computergenerated block randomization procedure (block size of six). Randomization was stratified by the kind and number of operation segments.

Allocation concealment was achieved by enclosing the assigned protocols in sealed, opaque, sequentially numbered envelopes, which were opened only after the arrival of the patient in the operating theatre. Blinding of research personnel and patients was maintained throughout the entire observation period including all postoperative follow-ups. Ye Zhang and Jinqiu Zhao generated the random allocation sequence. Qinsong Ren and Zhengxue Quan enrolled participants. Wei Zhang and Shuai Xu assigned participants to interventions. Bin $\mathrm{He}$ and Muzi Zhang uniformly prepared the study drugs. Ye Zhang, Jinqiu Zhao and Yunsheng $\mathrm{Ou}$ collected the data. Anesthesiologists' team was random for the surgeries.

\section{Study Intervention}

The typical analgesia methods for all patients mainly included $1.5-2 \mathrm{mg} / \mathrm{kg}$ of propofol followed by $4-12 \mathrm{mg} / \mathrm{kg} / \mathrm{h}, 1 \mathrm{mg} / \mathrm{kg}$ of rocuronium and remifentanil $0.1-0.2 \mu \mathrm{g} / \mathrm{kg} / \mathrm{min}$. Patients in the combination analgesia group obtained oral $400 \mathrm{mg}$ celebrex and $150 \mathrm{mg}$ pregabalin $2 \mathrm{~h}$ before surgery, then celebrex $200 \mathrm{mg}$ and $75 \mathrm{mg}$ pregabalin twice daily after surgery for 7 days plus subcutaneous infiltration of $0.75 \%$ ropivacaine (total $150 \mathrm{mg}, 20 \mathrm{~mL}$ ) at the end of surgery. Oral placebo capsule and subcutaneous infiltration of $0.75 \%$ ropivacaine at the end of surgery were administered in the ropivacaine group. Patients in the control group received oral placebo capsule and subcutaneous infiltration of $0.9 \%$ normal saline solution using the identical application scheme. $0.75 \%$ ropivacaine was prepared for the subcutaneous infiltration. 


\section{Outcome Measures and Safety}

We recorded the baseline characteristics of each patient, including age, sex, height, weight, intraoperative bleeding volume, operative time and preoperative pain.

Primary outcome was visual analog scale (VAS) scores at $12 \mathrm{~h}$ after surgery. Secondary outcomes included: (i) VAS scores at 0 h, $2 \mathrm{~h}, 24 \mathrm{~h}, 3 \mathrm{~d}, 5 \mathrm{~d}, 7 \mathrm{~d}$ and $14 \mathrm{~d}$ after surgery; (ii) the required dose of patient-controlled analgesia (PCA, continuous infusion of tramadol hydrochloride $800 \mathrm{mg}$ [Grunenthal $\mathrm{GmbH}$, Germany] and flurbiprofen $100 \mathrm{mg}$ [TIDE Pharmaceutical Co., China] in $84 \mathrm{~mL}$ saline solution); (iii) walking time, indicating the day on which patients could get up and walk; (iv) hospital stay after surgery; (v) adverse events such as nausea, vomiting, fever and infection. All patients were closely monitored for the occurrence of adverse events. Pain intensity levels were evaluated by VAS scores with a range of $0-10$, and 10 indicated the most serious pain.

\section{Statistical Analysis}

\section{Sample Size Calculation}

The sample size estimation was based on data from our clinical routine. In 30 arbitrarily chosen patients undergoing posterior spinal surgery before the start of the study, VAS scores at $12 \mathrm{~h}$ postoperatively were documented. The pilot data (VAS score at $12 \mathrm{~h}$ postoperatively) from 30 patients were as follows: combination analgesia group, 2.7 (standard deviation [SD], 0.65); ropivacaine group, $3.3(\mathrm{SD}, 0.65)$; and control group, 4.2 (SD, 1.03).
Assuming this difference and aiming for a power of $75 \%$ and a risk of 0.05 for a type- 1 error, 25 patients were required for each group. We selected 30 patients per group to allow for a $20 \%$ dropout rate.

\section{Data Analysis}

The statistical analysis was primarily conducted on an intention-to-treat basis using IBM SPSS Statistics v.25 (IBM Corp., USA). Variables were tested for normal distribution by the Kolmogorov-Smirnov test. Data were presented as mean (SD), medians (lower and upper quartiles) or frequencies, as appropriate. Data that followed a normal distribution (height) were compared using oneway analysis of variance (ANOVA). Kruskal-Wallis test was used for data that were not normally distributed (age, weight, bleeding volume, operative time, preoperative pain, VAS scores at $0 \mathrm{~h}, 2 \mathrm{~h}, 12 \mathrm{~h}, 24 \mathrm{~h}, 3 \mathrm{~d}, 5 \mathrm{~d}, 7$ $\mathrm{d}$ and $14 \mathrm{~d}$ after the surgery, PCA dose, walking time, hospital stay after surgery). Categorical data were analyzed using the $\chi^{2}$ test or Fisher exact test if any cells expected counts less than 5 . P-value of $<0.05$ was considered to indicate statistical significance.

\section{Results}

The study flow chart is shown in Figure 1. A total of 102 patients planned for elective posterior spinal surgery were screened; 93 patients were randomized to combination analgesia group $(\mathrm{n}=31)$, ropivacaine group $(\mathrm{n}=30)$ or control group $(\mathrm{n}=32)$. All patients received their allocated treatment and were included in the intention-to-treat population.

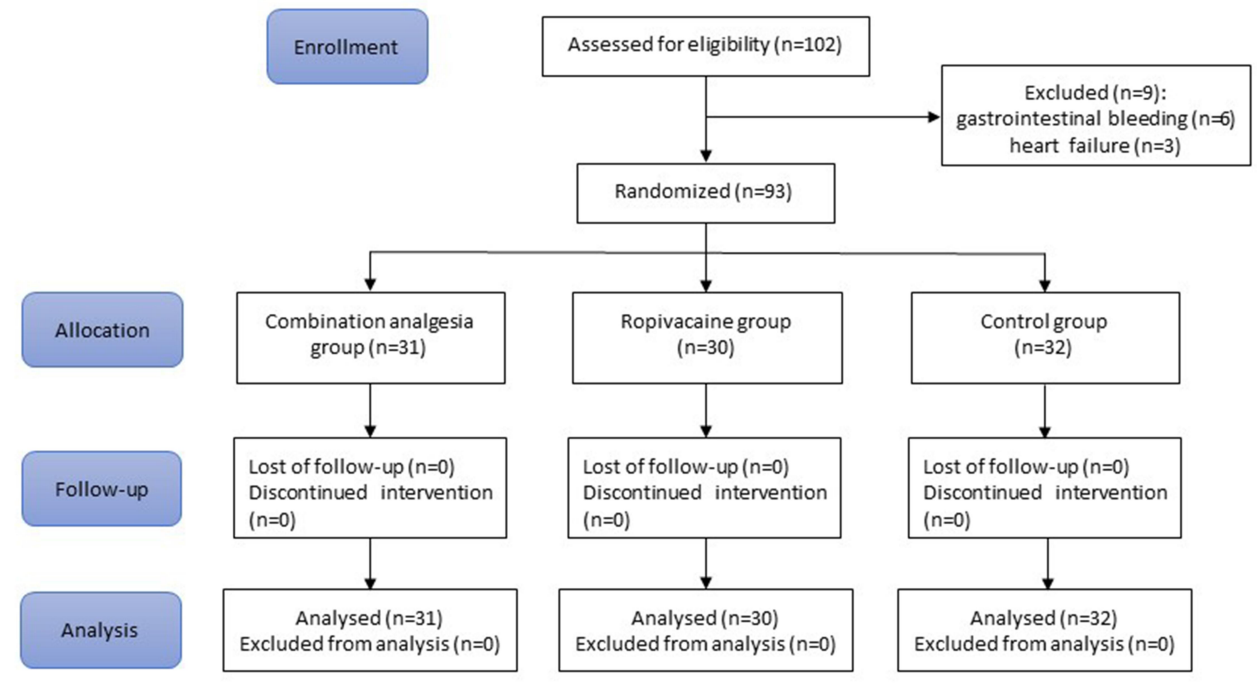

Figure I CONSORT flow chart. 


\section{Preoperative Assessment and}

\section{Intraoperative Data}

Patients in all groups did not differ significantly with respect to patient characteristics including age, sex, height, weight, intraoperative bleeding volume, operative time and preoperative pain $(\mathrm{P}>0.05$, Table 1$)$.

\section{Primary Outcome}

Compared with the control group, there were significantly lower VAS scores at $12 \mathrm{~h}$ after posterior spinal surgery in the combination analgesia group $(\mathrm{P}<0.001)$ and ropivacaine group $(\mathrm{P}<0.001)$. The combination analgesia intervention showed a decrease in VAS scores compared with the ropivacaine group, but with no significant difference $(\mathrm{P}=0.058$, Table 2$)$.

\section{Secondary Outcomes}

At $0 \mathrm{~h}, 2 \mathrm{~h}$ and $3 \mathrm{~d}$ after surgery, the VAS scores were significantly lower in the combination analgesia group and the ropivacaine group compared with the control group $(\mathrm{P}<0.001$ for $0 \mathrm{~h}$ and $2 \mathrm{~h}, \mathrm{P}=0.025$ for $3 \mathrm{~d}$ between

Table I Demographic Data and Clinical Characteristics of the Patients

\begin{tabular}{|c|c|c|c|c|c|c|}
\hline & $\begin{array}{c}\text { Combination } \\
\text { Analgesia Group }\end{array}$ & $\begin{array}{l}\text { Ropivacaine } \\
\text { Group }\end{array}$ & $\begin{array}{l}\text { Control } \\
\text { Group }\end{array}$ & $\begin{array}{c}\text { Combination } \\
\text { Analgesia vs } \\
\text { Ropivacaine } \\
\text { Group }\end{array}$ & $\begin{array}{l}\text { Combination } \\
\text { Analgesia vs } \\
\text { Control } \\
\text { Group }\end{array}$ & $\begin{array}{c}\text { Ropivacaine } \\
\text { Group vs } \\
\text { Control } \\
\text { Group }\end{array}$ \\
\hline Number & 31 & 30 & 32 & \multicolumn{3}{|c|}{$P$ value } \\
\hline Age (year) & $\begin{array}{c}59(50,68), \text { median } \\
\text { (lower, upper quartiles) }\end{array}$ & $59.5(51,66.5)$ & $\begin{array}{c}55.5 \\
(48.25,66.5)\end{array}$ & \multicolumn{3}{|c|}{0.793} \\
\hline Sex (male/female) & $15 / 16$ & $15 / 15$ & $16 / 16$ & \multicolumn{3}{|c|}{0.989} \\
\hline Height $(\mathrm{cm})$ & 164.55 (7.58) mean (SD) & $165.17(7.32)$ & $164.72(7.86)$ & 0.751 & 0.929 & 0.817 \\
\hline Weight (kg) & $56(48,70)$ & $58(49,7 \mathrm{I})$ & $60(52,70.25)$ & \multicolumn{3}{|c|}{0.708} \\
\hline Bleeding volume (mL) & $100(80,150)$ & $100(80,150)$ & $100(80,150)$ & \multicolumn{3}{|c|}{0.918} \\
\hline Operative time ( $\mathrm{min})$ & $160(120,180)$ & $162.5(120,180)$ & $150(120,180)$ & \multicolumn{3}{|c|}{0.717} \\
\hline Preoperative pain (VAS) & $5(4,5)$ & $5(4,5)$ & $5(4,5)$ & \multicolumn{3}{|c|}{0.621} \\
\hline
\end{tabular}

Note: Data are expressed as mean (standard deviation, SD), median (lower and upper quartiles) or frequency (n).

Table 2 Postoperative VAS Scores Among the Three Groups

\begin{tabular}{|c|c|c|c|c|c|c|}
\hline & $\begin{array}{c}\text { Combination } \\
\text { Analgesia } \\
\text { Group }\end{array}$ & $\begin{array}{c}\text { Ropivacaine } \\
\text { Group }\end{array}$ & $\begin{array}{l}\text { Control } \\
\text { Group }\end{array}$ & $\begin{array}{c}\text { Combination } \\
\text { Analgesia vs } \\
\text { Ropivacaine Group }\end{array}$ & $\begin{array}{l}\text { Combination } \\
\text { Analgesia vs } \\
\text { Control Group }\end{array}$ & $\begin{array}{c}\text { Ropivacaine } \\
\text { Group vs } \\
\text { Control Group }\end{array}$ \\
\hline Number & 31 & 30 & 32 & \multicolumn{3}{|c|}{$P$ value } \\
\hline $\begin{array}{l}\text { Primary outcome } \\
\qquad 12 \mathrm{~h}\end{array}$ & $3(2,3)$ & $3(3,4)$ & $4(4,5)$ & 0.058 & $<0.001$ & $<0.001$ \\
\hline Secondary outcome & & & & & & \\
\hline $\mathrm{Oh}$ & $2(2,2)$ & $2(2,3)$ & $4(3,4)$ & $>0.9$ & $<0.001$ & $<0.001$ \\
\hline $2 \mathrm{~h}$ & $2(2,3)$ & $2(2,3)$ & $4(4,4.75)$ & $>0.9$ & $<0.001$ & $<0.001$ \\
\hline $24 \mathrm{~h}$ & $3(2,3)$ & $4(3,4)$ & $4(3,5)$ & 0.005 & $<0.001$ & 0.148 \\
\hline $3 d$ & $3(2,3)$ & $3(2,3.25)$ & $3.5(3,4)$ & 0.117 & $<0.001$ & 0.025 \\
\hline $5 d$ & $2(2,3)$ & $3(2,3)$ & $3(3,3)$ & 0.271 & $<0.001$ & 0.107 \\
\hline $7 d$ & $2(1,2)$ & $2(2,2)$ & $2(2,3)$ & 0.193 & $<0.001$ & 0.091 \\
\hline $14 \mathrm{~d}$ & $\mathrm{I}(\mathrm{I}, \mathrm{I})$ & $2(1,2)$ & $2(1,2)$ & 0.005 & $<0.001$ & $>0.9$ \\
\hline PCA dose & $40(28,50)$ & $49(42.25,55)$ & $55(40,66)$ & 0.06 & 0.001 & 0.765 \\
\hline
\end{tabular}

Note: Data are expressed as median (lower and upper quartiles).

Abbreviation: PCA, patient-controlled analgesia. 
ropivacaine group and control group), but there was no statistical difference in VAS scores between the combination analgesia group and the ropivacaine group $(\mathrm{P}>0.05)$. At 24 $h$ after surgery, the VAS scores were also significantly lower in the combination analgesia group than the ropivacaine group $(\mathrm{P}=0.005)$ and the control group $(\mathrm{P}<0.001)$, while no statistical difference was observed between the ropivacaine group and the control group $(\mathrm{P}=0.148$, Table 2$)$.

At $5 \mathrm{~d}$ and $7 \mathrm{~d}$ after surgery, only patients in the combination analgesia group and ropivacaine group had markedly lower VAS scores than those in the control group $(\mathrm{P}<0.001)$. At $14 \mathrm{~d}$ postoperatively, the combination analgesia group had significantly lower VAS scores than the ropivacaine group and the control group ( $\mathrm{P} \leq 0.005)$, while the ropivacaine group and the control group demonstrated similar VAS scores $(\mathrm{P}>0.9)$. Cumulative PCA consumption in the combination analgesia group was significantly lower than that in the control group $(\mathrm{P}=0.001)$ (Table 2$)$. There were similar walking times and hospital stays after surgery among the three groups ( $\mathrm{P}>0.05$, Table 3$)$.

\section{Safety}

Adverse events were found in six patients (one case in the combination analgesia group, two cases in the ropivacaine group, and three cases in the control group). Nausea and vomiting occurred in one patient in the combination analgesia group and two patients in the control group. One patient in the ropivacaine group had a fever. Superficial wound infection was observed in one patient in the ropivacaine group, and this patient obtained wound healing after debridement and suturing under local anesthesia. One case in the control group had a deep wound infection, and underwent secondary surgery for debridement under general anesthesia.
Another case in the control group developed a urination disorder. There was no statistical difference in adverse events among the three groups and they were all well tolerable after immediate treatment (Table 3).

\section{Discussion}

The results of this study confirmed that postoperative VAS scores and PCA consumption after posterior spinal surgery were significantly reduced by preemptive and multimodal analgesia using celebrex, pregabalin and ropivacaine. However, this combination analgesia showed no significant impact on walking time or hospital stay after surgery. There was no increase in adverse events after combination analgesia intervention for posterior spinal surgery.

Preemptive and multimodal analgesia are two novel concepts to improve the efficacy of pain management. ${ }^{17,18}$ The pathophysiology of surgical pain includes peripheral sensitization initiated by inflammatory mediators and central sensitization resulting from hyperexcitability of the spinal neurons in the dorsal horn. ${ }^{18,19}$ Preemptive analgesia requires the administration of analgesics prior to surgery and aims to prevent this hyperexcitability of the central nervous system. ${ }^{20,21}$ Various analgesics are combined in multimodal analgesia and act through different mechanisms and at different sites in order to provide more effective analgesia. ${ }^{22,23}$

Celebrex, a cyclooxygenase (COX)-2 inhibitor, acts via suppressing COX-2-mediated production of prostaglandin E2 which is a product of arachidonic metabolism and promotes the pain and hyperalgesia associated with tissue trauma and inflammation. ${ }^{24}$ Celebrex is able to reduce the hyperalgesic state after surgical trauma through inhibiting the synthesis of prostaglandins in the spinal cord and the

Table 3 Postoperative Outcomes and Adverse Events

\begin{tabular}{|l|c|c|c|c|c|c|}
\hline & $\begin{array}{c}\text { Combination } \\
\text { Analgesia } \\
\text { Group }\end{array}$ & $\begin{array}{c}\text { Ropivacaine } \\
\text { Group }\end{array}$ & $\begin{array}{c}\text { Control } \\
\text { group }\end{array}$ & $\begin{array}{c}\text { Combination } \\
\text { Analgesia vs } \\
\text { Ropivacaine Group }\end{array}$ & $\begin{array}{c}\text { Combination } \\
\text { Analgesia vs } \\
\text { Control Group }\end{array}$ & $\begin{array}{c}\text { Ropivacaine } \\
\text { Group vs } \\
\text { Control Group }\end{array}$ \\
\hline Number & 31 & 30 & 32 & & P value \\
Walking time & $2(2,2)$ & $2(2,2)$ & $2(2,3)$ & 0.207 \\
Hospital stay after surgery & $4(4,5)$ & $5(4,5)$ & $5(4,5)$ & 0.388 \\
Adverse events & $\mathrm{I}$ & 2 & 3 & 0.610 \\
Nausea and vomiting & $\mathrm{I}$ & 0 & 2 & 0.771 \\
Fever & 0 & $\mathrm{I}$ & 0 & 0.323 \\
Infection & 0 & $\mathrm{I}$ & $\mathrm{I}$ & & 0.768 \\
Secondary surgery & 0 & 0 & $\mathrm{I}$ & & $\mathrm{I}$ \\
Urination disorders & 0 & 0 & $\mathrm{I}$ & & $\mathrm{I}$ \\
\hline
\end{tabular}

Note: Data are expressed as median (lower and upper quartiles) or frequency (n). 
periphery. $^{25,26}$ Pregabalin is developed as an anticonvulsant drug and inhibits central sensitization and the release of nociceptive neurotransmitters in the spinal cord through presynaptic and postsynaptic inhibition of calcium influx. $^{27-29}$ Anticonvulsants have been documented to diminish postoperative pain and opioid requirements after spinal surgery. ${ }^{11}$

Celebrex and pregabalin act through different mechanisms and their combination shows a synergistic effect for postoperative pain control. ${ }^{23}$ In one RCT that enrolled patients undergoing total hip arthroplasty, celecoxib plus pregabalin was associated with remarkably improved pain relief and physical function. ${ }^{14}$ However, there have been limited studies exploring the combination of celecoxib and pregabalin for spinal surgery. Preoperative administration of pregabalin combined with celecoxib (preoperative pregabalin and celecoxib) resulted in reduced VAS scores and intravenous morphine consumption after lumbar surgery, but that study only reported the efficacy during $48 \mathrm{~h}^{30}$ This study intended to investigate the effects of preemptive analgesia (preoperative oral administration of celebrex and pregabalin) and multimodal analgesia (celebrex and pregabalin combined with subcutaneous infiltration of ropivacaine) on postoperative pain up to $14 \mathrm{~d}$ after posterior spinal surgery.

Local wound infiltration of anesthetics has been developed into a useful and important component of the multimodality approach to postoperative pain control through reducing the sensitization of spinal dorsal horn neurons and inhibiting the transmission of noxious impulses from the incision. ${ }^{31}$ It can also suppress local inflammatory responses to incision injury. ${ }^{32}$ Local infiltration of anesthetics has shown some potential in pain relief after breast surgery and inguinal hernia repair. ${ }^{33,34}$ Ropivacaine, a pure levorotatory stereoisomer and long-acting amide local anesthetic agent, has been widely used for local anesthesia and postoperative analgesia. Ropivacaine has the same analgesic effects as bupivacaine and levobupivacaine, but shows lower incidence of motor block. ${ }^{35}$ There is decreased incidence of central nervous system toxicity and cardiotoxicity because of the reduced lipophilicity of ropivacaine. ${ }^{36}$

In this study, preemptive and multimodal analgesia using celebrex, pregabalin and ropivacaine significantly reduced VAS scores up to $14 \mathrm{~d}$ postoperatively and PCA consumption after posterior spinal surgery. This preemptive and multimodal analgesia is safe and well tolerable, showing no increase in adverse events. Our study is subject to a few limitations. Firstly, clinical pain in our patients is evaluated using the VAS score, instead of using quantitative sensory testing (QST) which is a well-validated experimental tool for evaluating and quantifying hyperalgesia with a stimulusresponse gradient. ${ }^{37,38}$ Secondly, different procedures of operation are included in this study, and may have some influence on the analgesic evaluation. Thirdly, recent research has demonstrated sex differences with respect to pain perception, ${ }^{39}$ but we did not perform a subgroup analysis based on sex difference. Finally, PCA was discontinued if patients had severe nausea and vomiting, which may affect the comparison of PCA consumption among groups.

To the best of our knowledge, this is the first clinical report to explore the effect of preemptive analgesia (preoperative administration of celebrex and pregabalin) and multimodal analgesia (oral celebrex and pregabalin combined with subcutaneous infiltration of ropivacaine) on postoperative pain up to $14 \mathrm{~d}$ after posterior spinal surgery. Our results suggest that this preemptive and multimodal analgesia can effectively and safely alleviate postoperative pain for posterior spinal surgery.

\section{Data Sharing Statement}

The datasets generated during and/or analyzed during the current study are available in the ResMan Research Manager repository (http://www.medresman.org.cn/uc/sin dex.aspx).

\section{Ethics Statement}

The study protocol was approved by the Ethics Committee of The First Affiliated Hospital of Chongqing Medical University. The study has been registered in the Chinese Clinical Trial Registry (ChiCTR2000031236). Written informed consent was obtained from all patients.

\section{Acknowledgments}

This study was funded by Foundation of The First Affiliated Hospital of Chongqing Medical University (PYJJ2018-13) and Natural Science Foundation of Chongqing (cstc2019jcyj-msxmX0836).

\section{Disclosure}

The authors declare no conflicts of interest in this work. 


\section{References}

1. Li D, Hai Y, Meng X, Yang J, Yin P. Topping-off surgery vs posterior lumbar interbody fusion for degenerative lumbar disease: a comparative study of clinical efficacy and adjacent segment degeneration. J Orthop Surg Res. 2019;14(1):197. doi:10.1186/ s13018-019-1245-3

2. Park MS, Ju YS, Moon SH, et al. Reoperation rates after posterior lumbar spinal fusion surgery according to preoperative diagnoses: a national population-based cohort study. Clin Neurol Neurosurg. 2019;184:105408. doi:10.1016/j.clineuro.2019.105408

3. Hwang W, Lee J, Park J, Joo J. Dexmedetomidine versus remifentanil in postoperative pain control after spinal surgery: a randomized controlled study. BMC Anesthesiol. 2015;15(1):21. doi:10.1186/s12871015-0004-1

4. Kim HJ, Ahn HS, Nam Y, Chang BS, Lee CK, Yeom JS. Comparative study of the efficacy of transdermal buprenorphine patches and prolonged-release tramadol tablets for postoperative pain control after spinal fusion surgery: a prospective, randomized controlled non-inferiority trial. Eur Spine J. 2017;26(11):2961-2968. doi:10.1007/s00586-017-5213-5

5. Panchamia JK, Amundson AW, Jacob AK, et al. A 3-arm randomized clinical trial comparing interscalene blockade techniques with local infiltration analgesia for total shoulder arthroplasty. J Shoulder Elbow Surg. 2019;28(10):e325-e338. doi:10.1016/j.jse.2019.05.013

6. Wilson MJA, MacArthur C, Hewitt CA, et al. Intravenous remifentanil patient-controlled analgesia versus intramuscular pethidine for pain relief in labour (RESPITE): an open-label, multicentre, randomised controlled trial. Lancet (London, England). 2018;392 (10148):662-672. doi:10.1016/S0140-6736(18)31613-1

7. Cooper HJ, Lakra A, Maniker RB, Hickernell TR, Shah RP, Geller JA. Preemptive analgesia with oxycodone is associated with more pain following total joint arthroplasty. J Arthroplasty. 2019;34 (12):2878-2883. doi:10.1016/j.arth.2019.07.021

8. Enthoven WTM, Roelofs PD, Koes BW. NSAIDs for chronic low back pain. JAMA. 2017;317(22):2327-2328. doi:10.1001/jama.2017.4571

9. Motov S, Yasavolian M, Likourezos A, et al. Comparison of intravenous ketorolac at three single-dose regimens for treating acute pain in the emergency department: a randomized controlled trial. Ann Emerg Med. 2017;70(2):177-184. doi:10.1016/j.annemergmed.2016.10.014

10. Stepan JG, London DA, Osei DA, Boyer MI, Dardas AZ, Calfee RP. Perioperative celecoxib and postoperative opioid use in hand surgery: a prospective cohort study. J Hand Surg. 2018;43(4):346-353. doi:10.1016/j.jhsa.2017.11.001

11. Yu L, Ran B, Li M, Shi Z. Gabapentin and pregabalin in the management of postoperative pain after lumbar spinal surgery: a systematic review and meta-analysis. Spine. 2013;38(22):1947-1952. doi:10.1097/BRS.0b013e3182a69b90

12. Jiang HL, Huang S, Song J, Wang X, Cao ZS. Preoperative use of pregabalin for acute pain in spine surgery: a meta-analysis of randomized controlled trials. Medicine. 2017;96(11):e6129. doi:10.1097/ MD.0000000000006129

13. Romano CL, Romano D, Bonora C, Mineo G. Pregabalin, celecoxib, and their combination for treatment of chronic low-back pain J Orthop Traumatol. 2009;10(4):185-191. doi:10.1007/s10195-0090077-z

14. Carmichael NM, Katz J, Clarke H, et al. An intensive perioperative regimen of pregabalin and celecoxib reduces pain and improves physical function scores six weeks after total hip arthroplasty: a prospective randomized controlled trial. Pain Res Manag. 2013;18(3):127-132. doi:10.1155/2013/258714

15. Kundra S, Singh RM, Singh G, Singh T, Jarewal V, Katyal S. Efficacy of magnesium sulphate as an adjunct to ropivacaine in local infiltration for postoperative pain following lower segment caesarean section. J Clin Diagn Res. 2016;10(4):Uc18-22. doi:10.7860/JCDR/2016/17119.7683
16. Andersen L, Husted H, Kristensen BB, Otte KS, Gaarn-Larsen L, Kehlet H. Analgesic efficacy of subcutaneous local anaesthetic wound infiltration in bilateral knee arthroplasty: a randomised, placebo-controlled, double-blind trial. Acta Anaesthesiol Scand. 2010;54(5):543-548. doi:10.1111/j.1399-6576.2009.02196.x

17. Kurd MF, Kreitz T, Schroeder G, Vaccaro AR. The role of multimodal analgesia in spine surgery. $J$ Am Acad Orthop Surg. 2017;25 (4):260-268. doi:10.5435/JAAOS-D-16-00049

18. Kaka U, Rahman NA, Abubakar AA, et al. Pre-emptive multimodal analgesia with tramadol and ketamine-lidocaine infusion for suppression of central sensitization in a dog model of ovariohysterectomy. $J$ Pain Res. 2018;11:743-752. doi:10.2147/JPR.S152475

19. Woolf CJ, Salter MW. Neuronal plasticity: increasing the gain in pain. Science (New York, NY). 2000;288(5472):1765-1769. doi:10.1126/science.288.5472.1765

20. Steinberg AC, Schimpf MO, White AB, et al. Preemptive analgesia for postoperative hysterectomy pain control: systematic review and clinical practice guidelines. Am J Obstet Gynecol. 2017;217(3):303313.e306. doi:10.1016/j.ajog.2017.03.013

21. Peng HM, Wang LC, Wang W, et al. Preemptive analgesia with parecoxib in total hip arthroplasty: a randomized, double-blind, placebo-controlled trial. Pain Physician. 2018;21(5):483-488.

22. Lamplot JD, Wagner ER, Manning DW. Multimodal pain management in total knee arthroplasty: a prospective randomized controlled trial. $J$ Arthroplasty. 2014;29(2):329-334. doi:10.1016/j. arth.2013.06.005

23. Kim SI, Ha KY, Oh IS. Preemptive multimodal analgesia for postoperative pain management after lumbar fusion surgery: a randomized controlled trial. Eur Spine J. 2016;25(5):1614-1619. doi:10.1007/s00586-015-4216-3

24. Angeli F, Trapasso M, Signorotti S, Verdecchia P, Reboldi G. Amlodipine and celecoxib for treatment of hypertension and osteoarthritis pain. Expert Rev Clin Pharmacol. 2018;11(11):1073-1084. doi:10.1080/17512433.2018.1540299

25. Shin JJ, McCrum CL, Mauro CS, Vyas D. Pain management after hip arthroscopy: systematic review of randomized controlled trials and cohort studies. Am J Sports Med. 2018;46(13):3288-3298. doi: $10.1177 / 0363546517734518$

26. Puljak L, Marin A, Vrdoljak D, Markotic F, Utrobicic A, Tugwell P. Celecoxib for osteoarthritis. Cochrane Database Syst Rev. 2017;5(5): Cd009865. doi:10.1002/14651858.CD009865.pub2

27. Derry S, Bell RF, Straube S, Wiffen PJ, Aldington D, Moore RA. Pregabalin for neuropathic pain in adults. Cochrane Database Syst Rev. 2019;1(1):Cd007076. doi:10.1002/14651858.CD007076.pub3

28. Rai AS, Khan JS, Dhaliwal J, et al. Preoperative pregabalin or gabapentin for acute and chronic postoperative pain among patients undergoing breast cancer surgery: a systematic review and meta-analysis of randomized controlled trials. $J$ Plast Reconstr Aesthet Surg. 2017;70(10):1317-1328. doi:10.1016/j.bjps.2017.0 5.054

29. Goodman CW, Brett AS. Gabapentin and pregabalin for pain - is increased prescribing a cause for concern? N Engl J Med. 2017;377 (5):411-414. doi:10.1056/NEJMp1704633

30. Kien NT, Geiger P, Van Chuong H, et al. Preemptive analgesia after lumbar spine surgery by pregabalin and celecoxib: a prospective study. Drug Des Devel Ther. 2019;13:2145-2152. doi:10.2147/ DDDT.S202410

31. Brennan TJ, Zahn PK, Pogatzki-Zahn EM. Mechanisms of incisional pain. Anesthesiol Clin North Am. 2005;23(1):1-20. doi:10.1016/j. atc.2004.11.009

32. Kawamata M, Takahashi T, Kozuka Y, et al. Experimental incision-induced pain in human skin: effects of systemic lidocaine on flare formation and hyperalgesia. Pain. 2002;100(1):77-89. doi:10.1016/S0304-3959(02)00233-6

33. Scott NB. Wound infiltration for surgery. Anaesthesia. 2010;65(Suppl 1):67-75. doi:10.1111/j.1365-2044.2010.06241.x 
34. Byager N, Hansen MS, Mathiesen O, Dahl JB. The analgesic effect of wound infiltration with local anaesthetics after breast surgery: a qualitative systematic review. Acta Anaesthesiol Scand. 2014;58 (4):402-410. doi:10.1111/aas.12287

35. Li M, Wan L, Mei W, Tian Y. Update on the clinical utility and practical use of ropivacaine in Chinese patients. Drug Des Devel Ther. 2014;8:1269-1276. doi:10.2147/DDDT.S57258

36. Kuthiala G, Chaudhary G. Ropivacaine: a review of its pharmacology and clinical use. Indian J Anaesth. 2011;55(2):104-110. doi:10.4103/ 0019-5049.79875

37. Martinez V, Fletcher D, Bouhassira D, Sessler DI, Chauvin M. The evolution of primary hyperalgesia in orthopedic surgery: quantitative sensory testing and clinical evaluation before and after total knee arthroplasty. Anesth Analg. 2007;105(3):815-821. doi:10.1213/01. ane.0000278091.29062.63
38. Wilder-Smith Oliver HGPD, Tassonyi EPD, Crul Ben JPPD, ArendtNielsen LPD. Quantitative sensory testing and human surgery: effects of analgesic management on postoperative neuroplasticity. Anesthesiology. 2003;98(5):1214-1222. doi:10.1097/00000542-200305000-00025

39. Bartley EJ, Fillingim RB. Sex differences in pain: a brief review of clinical and experimental findings. Br J Anaesth. 2013;111(1):52-58. doi:10.1093/bja/aet127

\section{Publish your work in this journal}

Drug Design, Development and Therapy is an international, peerreviewed open-access journal that spans the spectrum of drug design and development through to clinical applications. Clinical outcomes, patient safety, and programs for the development and effective, safe, and sustained use of medicines are a feature of the journal, which has also been accepted for indexing on PubMed Central. The manuscript management system is completely online and includes a very quick and fair peer-review system, which is all easy to use. Visit http://www. dovepress.com/testimonials.php to read real quotes from published authors. 